\title{
VERTICAL MARGINAL GAP AND INTERNAL FIT OF TWO TYPES OF FULLY ANATOMIC ZIRCONIA CROWNS CONSTRUCTED BY DIFFERENT CAD/CAM SYSTEM
}

\author{
Tarek Abdel Hamid*, Diaaeldin Saad Awad", Mosaad Aly Al-gabrouny *** and Osama Atta***
}

\begin{abstract}
Objective: To evaluate the vertical marginal gap and internal fit of two types of monolithic zirconia crowns fabricated using two different $\mathrm{CAD} / \mathrm{CAM}$ machines.

Materials and methods: A sound human maxillary first premolar was selected to receive all ceramic crown preparation. The prepared premolar was then duplicated to produce twenty epoxy dies divided into two groups. Twenty Standardized monolithic translucent zirconia (10 Prettau, \& 10 Incoris TZI crowns) were CAD/CAM fabricated onto the epoxy dies. The vertical marginal gap before cementation was measured using a metallurgic microscope. Then the crowns were cemented onto their corresponding epoxy dies using Panavia F 2.0. Half of the specimens were sectioned bucco-lingualy and the remaining specimens were sectioned mesio-distally. Measurements of the internal fit on the Buccal, lingual, mesial, distal and occlusal were taken using a metallurgic microscope. Results were tabulated and statistically analyzed using Wilcoxon signed rank test.
\end{abstract}

Results: The Prettau crowns showed statistically significantly higher vertical marginal gap (Prettau 96.91 $\pm 2.78 \&$ Incoris TZI $59.17 \pm 6.4 \mu \mathrm{m}$ ) and inferior internal fit than that of Incoris TZI crowns (Prettau $117 \pm 3.67 \&$ Incoris TZI $103.2 \pm 3.61 \mu \mathrm{m})$.

Conclusions: The Incoris TZI crowns had better marginal integrity and internal fit than that of Prettau crowns.

\section{INTRODUCTION}

Zirconia provided a biocompatible esthetic material for the restoration of teeth as alternative to metal- ceramics. ${ }^{1,2,3}$ The use of CAD/CAM milling technology has been adopted as the main dental processing technique for zirconia., ${ }^{4,5}$ The fabrication of full contour anatomic zirconia crowns has provided an alternative to the porcelain-veneered crowns with excellent strength and high fracture resistance due the absence of a super structure (veneer). However the long-term clinical success of full contour zirconia crowns is not dependent only on the mechanical properties, esthetic quality

\footnotetext{
* Lecturer of Crown \& Bridge, Department of Crown \& Bridge, Faculty of Dentistry, Suez Canal University, Ismailia, Egypt ** Professor \& Head of Crown \& Bridge Department, Faculty of Dentistry, Suez Canal Universit, Ismailia, Egypt *** Professor of Crown \& Bridge, Department of Crown \& Bridge, Faculty of Dentistry, Suez Canal University, Ismailia, Egypt
} 
and biocompatibility but also on the marginal integrity and internal fit. Large marginal gaps lead to dissolution of the cement with subsequent dental plaque accumulation facilitating marginal leakage and secondary decay. ${ }^{7,8}$ It is well agreed in the literature that marginal fit is one of the major factors responsible for causing secondary decay and periodontal disease..$^{9,10,11}$ It has been proven by McLean $^{12}$ in 1971 that clinically allowable marginal fit is within $120-\mu \mathrm{m}$ range when fabricating a dental restoration.

Over the last years, most studies on monolithic zirconia focused mainly on the mechanical properties (fracture resistance ${ }^{13}$, flexural strength \& chipping resistance ${ }^{14}$, and hardness ${ }^{15}$ ), the effect of surface treatment on the mechanical properties, the wear of the zirconia on the antagonists, ${ }^{16}$ and effect of the low temperature degradation. ${ }^{17}$

Little information is available about the marginal gap and internal fit of these restorations. Seok J.H. and $\mathrm{Jin} \mathrm{HC}^{18}$ reported that the marginal discrepancy and internal fit was smaller in Ceramill system than ZirkonZahn. However both were within clinically acceptable range of marginal discrepancy. Freire et al ${ }^{19}$ studied the marginal fit of monolithic restorations (monolithic zirconia Lava plus, monolithic lithium disilicate IPS Emax CAD, and conventional metal ceramic crowns. They found that the monithic lithium disilicate produced the lowest discrepancy and they concluded that the accuracy of fit of the three groups was within the range of clinical acceptance range.

So the aim of this study was to evaluate the vertical marginal gap and internal fit of two monolithitc zirconium crowns (Prettau and Incoris TZI) constructed by two different CAD/CAM systems(Zirkon Zahn,Italy and Cerec, Sirona ).

The null hypothesis tested in this study that there is no difference in the vertical marginal gap and internal fits between the two systems.

\section{MATERIALS AND METHODS}

\section{Tooth preparation and die fabrications}

A freshly extracted non-carious, non-restored sound permanent Upper human premolar was selected for this study. The tooth was mounted in an acrylic base to allow accurate positioning of the tooth in a milling machine (which was used for tooth preparation). The tooth was prepared using a milling machine (AF 30, Nouvag AG ST. Switzerland) (figure 1a) modified by custom made adaptor to accommodate high speed contra-angle (NSK, Tokyo, Japan). Tooth preparation was done using tapered diamond stone with flat end (TF 12, Mani Inc. Japan) and head diameter $1 \mathrm{~mm}$ so that the preparation had $1 \mathrm{~mm}$ shoulder finish line and 6 degree convergence angle (figure 1b) which was achieved by the taper of the diamond bur. Occlusal reduction was done after removing the tooth from the milling machine. Using a cylindrical diamond bur (SF 14, Mani Inc. Japan) with diameter of $1.5 \mathrm{~mm}$. Depth cut grooves of $1.5 \mathrm{~mm}$ were cut in the occlusal surface at $45^{\circ}$ angle with the long axis of the tooth. The prepared tooth had $6.5 \mathrm{~mm}$ height, $4 \mathrm{~mm}$ mesiodistal diameter and $7 \mathrm{~mm}$ bucco-palatal diameter at the cervical part. The preparation was finished by fine diamond stone at low speed. The prepared tooth was duplicated using silicon duplicating material [Dupliflex,Vilamalla (Girona) Spain ] and poured into 20 epoxy resin dies (Kemapoxy, CMB, Egypt) (figure 1c). The epoxy dies were then duplicated into twenty working stone dies for crown constructions using a scanable stone (Optic Scanning stone, ETI Empire Direct, Anaheim, CA, USA).

\section{Grouping of samples}

The twenty epoxy dies were divided into two groups $(n=10)$ according to the crowns constructed over it.

Group 1 : Prettau crowns

Group 2: Incoris TZI crowns 


\section{Construction of the crowns}

\section{Prettau crowns:}

Ten Prettau crowns were fabricated over ten working stone dies. For each crown to be fabricated a specific scan (S600, Zirkonzahn, Italy) for the respective die had to be taken. The crowns were designed using CAD software (Modellier V.5556, ZirkonZahn, Italy). The cement space thickness was adjusted on $60 \mu$ for all the crowns. Zirconia blocks (Prettau zirkon CAD-CAM95H22, Zirkonzahn, Italy) were milled( M1 Soft Milling, Zirkonzahn, Italy), in partially sintered stage considering of $20 \%$ shrinkage and fully sintered for 12 hours at $1600{ }^{\circ} \mathrm{C}$ in (Zirkonofen 700, Zirkonzahn, Italy). Sandblasting with $50 \mathrm{Al}_{2} \mathrm{O}_{3}$ at 4 bars was employed (20 sec, $15 \mathrm{~mm}$ distance) and then outer surface of crown was glazed using paste glaze Plus, using glaze firing cycle $\left(780-800{ }^{\circ} \mathrm{C}, 1 \mathrm{~min}\right.$ holding time $)$.

\section{Incoris TZI crowns:}

Ten scans with cerec 3D (inEos X5, Sirona Dental Systems GmbH, Germany) of the other ten stone dies were used with another scan of one of the fabricated Prettau crowns to produce ten Incoris TZI bio-copy crowns. Cerec software 4.3 (Sirona Dental Systems GmbH, Germany) was used for designing the restoration. The cement space thickness also was set on $60 \mu$ for all the crowns.

INcoris TZI C blocks (mono L, Sirona Dental Systems GmbH, Germany) were used. The blocks were milled in the partially sintered stage with the milling machine (MX5, Sirona Dental Systems $\mathrm{GmbH}$, Germany) and sintered in (inFire HTC, Sirona Dental Systems GmbH, Germany) for 2 hours at $1510{ }^{\circ} \mathrm{C}$. Sandblasting with $50 \mathrm{Al}_{2} \mathrm{O}_{3}$ at 3 bars was employed and then outer surface of crown was glazed using cerec speed Glaze spray.

\section{Measuring the vertical marginal gap:}

The crown specimens of both groups were employed for measuring the vertical marginal gap before cementation. In order to allow proper seating of the crown on the corresponding epoxy die a specially designed crown fixing device was used to hold the samples during microscopic measurements (Figure 2A). The crowns were seated on the corresponding dies, and then the assembly was mounted in the crown fixing device and the spring rod secured the crown in position. The whole assembly was placed on the mechanical stage of the microscope, and the microscope was focused at the crown / tooth margins. The vertical marginal gap was measured using metallurgic microscope (Olympus Bx41M, San-Ei bulding, 22-2, Nishi Shinjuku 1-chome, Shinjuku-Ku,Tokyo, Japan), with a

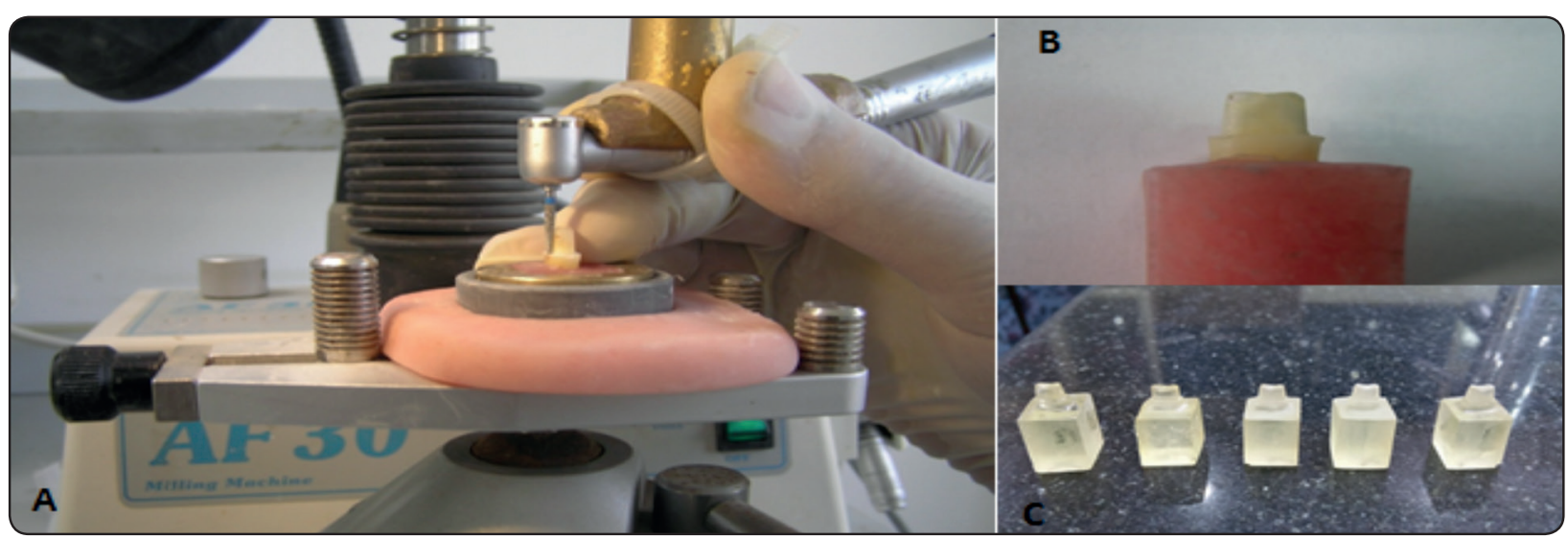

Fig. (1) Tooth preparation \& die fabrication, A: Tooth preparation with the milling machine, B: Tooth after complete preparation, C: duplicated Epoxy dies 


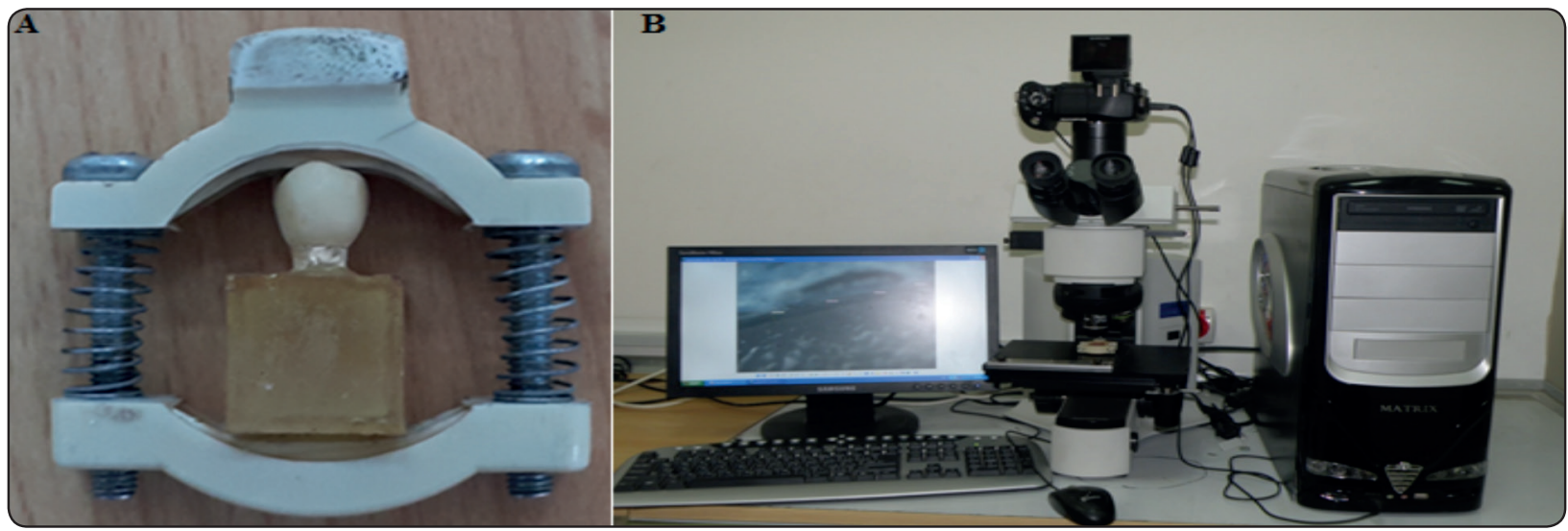

Fig. (2) Measuring the vertical marginal gap, A: Specially designed fixing device to allow proper seating of the crown on the die before cementation, B: Metallurgic microscope used to measure marginal gap \& internal fit

high-resolution digital camera (Olympus digital camera SP-570-UZ, San-Ei bulding, 22-2, Nishi Shinjuku 1-chome, Shinjuku-Ku, Tokyo, Japan) mounted on the microscope (Figure 2B). A software module Olympus Analysis five (Nishi Shinjuku 1-chome, Shinjuku-Ku, Tokyo, Japan) was used to analyze the images and the measurements were taken at a resolution of $1400 \times 1200$ pixels at magnification of $10 \mathrm{X}$.

After adjustment of the photo, which appeared on the LCD camera screen. A snap shot was taken and transferred to the computer screen automatically. Using the computer software the vertical marginal gap was measured on the screen in $\mu \mathrm{m}$. The vertical marginal gap was measured from the crown margin to the shoulder margin of the die. Eight readings, equidistant, were taken at each surface, that resulted in 32 readings for each sample

\section{Internal Fit measurement:}

The crown samples were cemented onto corresponding epoxy dies using Panavia F 2.0 adhesive resin cement following the manufacturer instructions. A specially designed device was used during cementation of the crowns that allow application of standardized $3 \mathrm{~kg}$ load (used in previous study). ${ }^{20}$ The cemented crowns were stored for 24 hours in water before sectioning and internal fit measurement. Half of the cemented crowns were sectioned in a bucco-lingual direction and the other half in a mesio-distal direction by the use of a low speed saw (Micracut 125, Metkon,Bursa, Turkey) as in Figure 3.

Measurement between the epoxy die and the internal surface of the sectioned crown were taken at eight points on the occlusal and each of the axial surfaces (bucco,lingual and mesio,distal) using a metallurgic microscope to give a total of 24 points of reading for the internal fit. For the axial surfaces the points of reading were distributed over the surface (four points at the cervical half \& four at the occlusal half). Data were tabulated and statistically analyzed using Wilcoxon signed rank test.

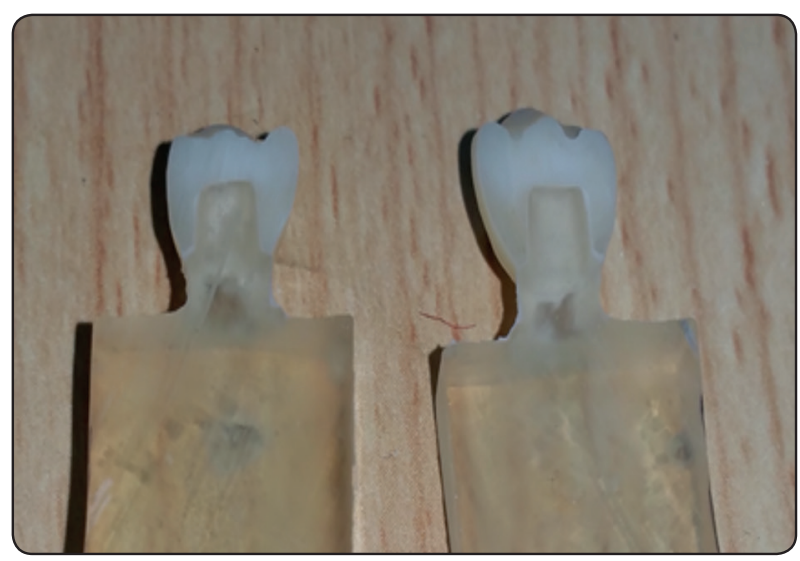

Fig. (3) The crown cemented onto the epoxy die and sectioned into two halves using low speed saw 


\section{RESULTS}

\section{Vertical marginal gap:}

The vertical marginal gap was recorded in $\mu \mathrm{m}$. The mean and standard deviation of the two groups are shown in Table 1 and presented in figure 4. The statistical analysis using Wilcoxon signed rank test revealed a statistically significant difference between the two types of crowns investigated, where the Prettau crowns showed a higher vertical marginal gap than that of the IncorisTZI crowns. Figures 5 and 6 show the vertical marginal gap in $\mu \mathrm{m}$ for both crowns.

TABLE (1) Vertical marginal gap $(\mu \mathrm{m})$ of both groups.

\begin{tabular}{|c|c|c|c|}
\hline & Prettau & Incoris TZI & p-value \\
\hline Mean \pm SD & $96.91 \pm 2.78$ & $59.17 \pm 6.4$ & $0.008^{*}$ \\
\hline
\end{tabular}

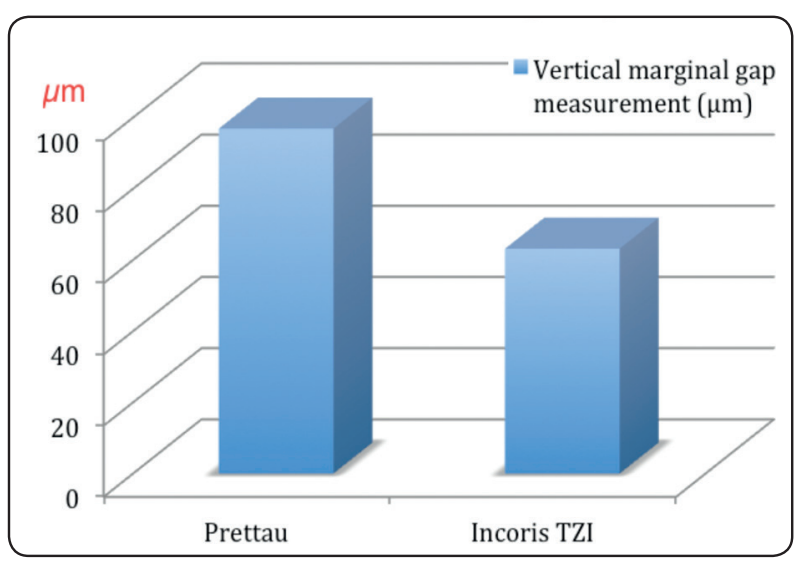

Fig. (4) Histogram showing vertical marginal gap of both groups.

\section{Internal Fit:}

The internal fit was measured and recorded in $\mu \mathrm{m}$. The mean and standard deviation of the Prettau and Incoris TZI crowns are shown in Table 2 and presented in Figure 7. Statistical analysis of the data showed a statically significant difference between the two groups using
Wilcoxon signed rank test, where the Incoris TZI crowns showed better internal fit than that of the Prettau crowns. Figures 8, 9 show the internal fit in $\mu \mathrm{m}$ for both types of zirconium crowns.

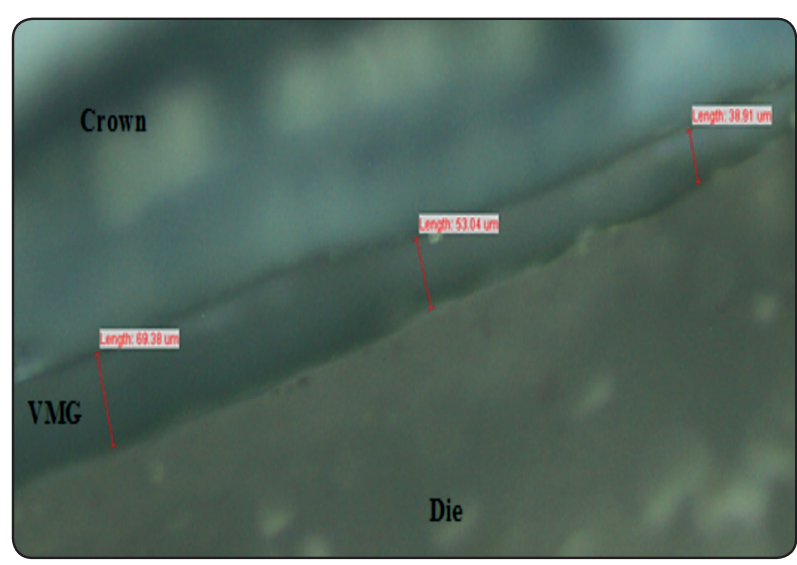

Fig. (5) Vertical Marginal Gap VMG before cementation for Incoris TZI Crowns (magnification 10X)

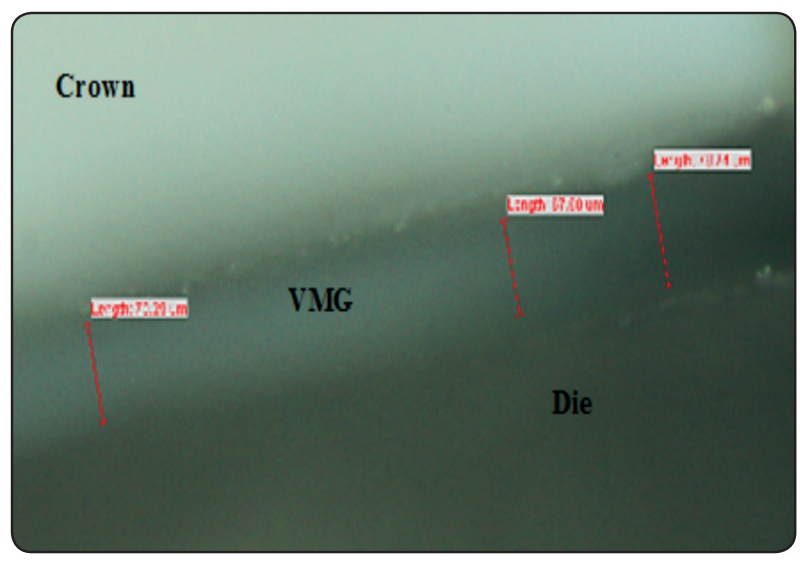

Fig. (6) Vertical Marginal Gap VMG before cementation for Prettau crown (magnification 10X)

TABLE (2) Internal fit in $(\mu \mathrm{m})$ for both groups.

\begin{tabular}{|c|c|c|c|}
\hline & Prettau & Incoris Tzi & p-value \\
\hline Mean \pm SD & $117 \pm 3.67$ & $103.2 \pm 3.61$ & $0.01 *$ \\
\hline
\end{tabular}




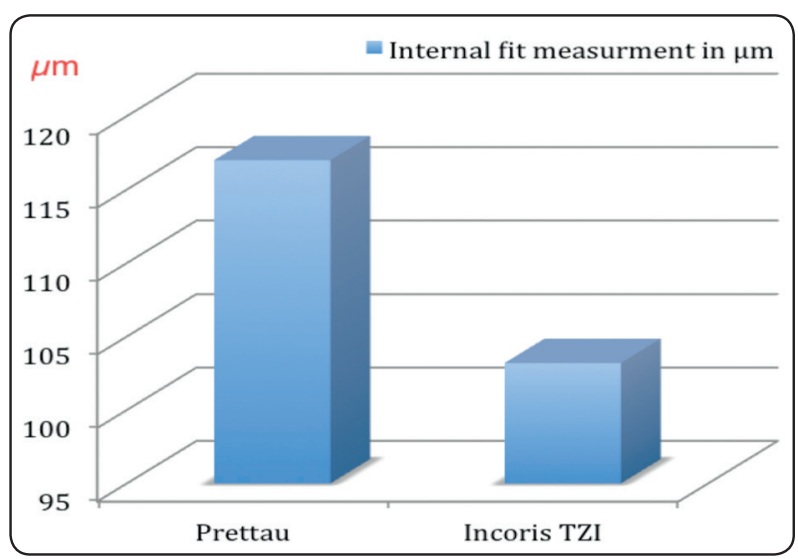

Fig. (7) Histogram showing internal fit measurement in $\mu \mathrm{m}$ for both groups.

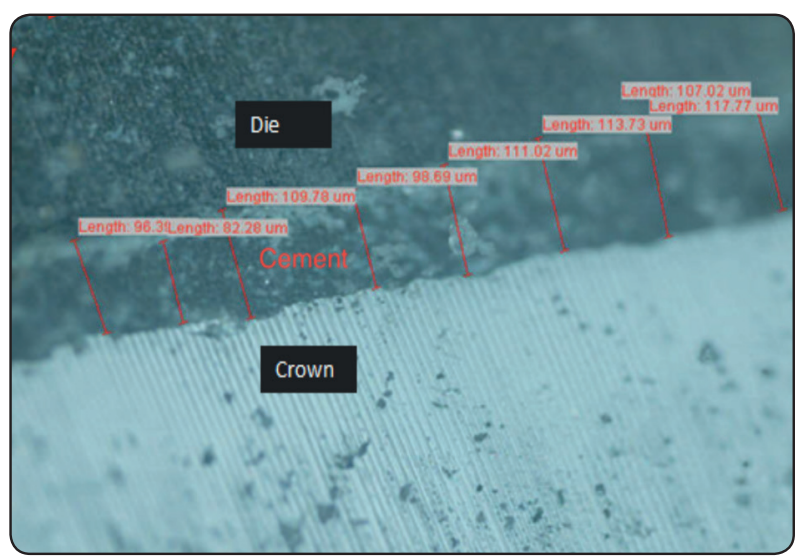

Fig. (8) Internal fit measurement of Incoris TZI crown.

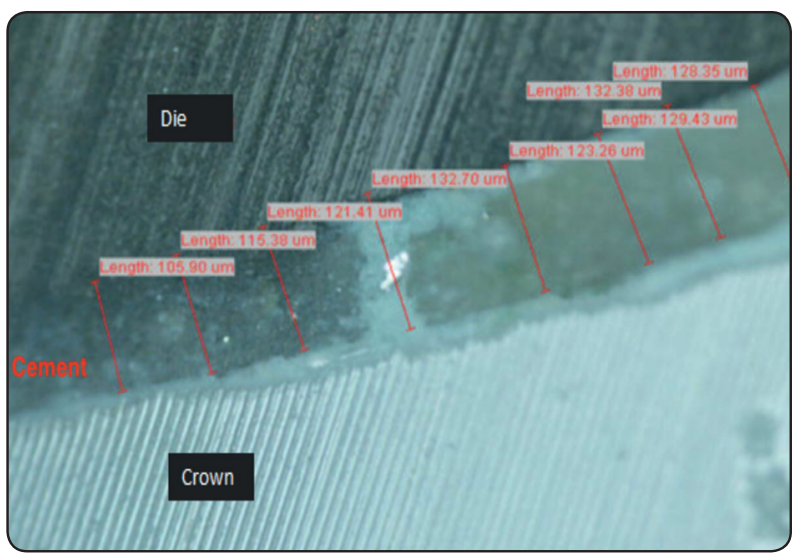

Fig. (9) Internal fit measurement of Prettau crown

\section{DISCUSSION}

The high restoration esthetic demand led to the emergence of different types of all ceramic restorations among which dental zirconia based restorations presented a promising result due to the high fracture resistance of zirconia. ${ }^{21}$ However the inherent clinical drawbacks of the veneered zirconia in terms of chipping and fractures of the veneer ${ }^{22}$ and de-bonding of the zirconia restoration paved the way for development of a new restoration without the drawback of veneering layer. This led to the introduction of translucent zirconia for constructing fully contoured dental restoration that provided a hope for a fracture resistant monolithic restoration.

A sound natural maxillary premolar tooth was prepared for a standard all ceramic crown preparation. The tooth preparation was undertaken by dental milling machine where the specimen were secured to the base of the milling machine while high speed contra-angle were mounted horizontally using water balance device so that the diamond stone would be hanging vertically to ensure that preparation of the axial wall angulations would be corresponding to the taper of the diamond stone which is 3 degree on each axial wall to give a total of 6 degree of convergence. The finish line used in this study was a rounded shoulder as recommended by the manufacturer of both types of translucent zirconia investigated in this study. In order to standardize the size and dimensions of the both types of zirconia crowns investigated in this study, the Prettau zirconia crowns was first fabricated on one of the dies after which they were copied to fabricate the Incoris TZI crowns using the Cerec SW 4.3 biocopy design mode. Standardization of cement space of the crowns was achieved by selecting 60 microns cement space on the CAD software of both systems employed in the study. Panavia F2.0 adhesive resin cement was the standard cement used in this study. After mixing the cement following the manufacturer instructions, seating of the crown on the die was 
standardized using specially designed cementation device, which allowed static placement of $3 \mathrm{Kg}$ load during the setting procedure. This load was chosen as recommended by Rinke et al $1995^{23}$ and Groten and Probester $19966^{24}$ to avoid the risk of damaging the ceramic crowns. The marginal gap and internal fit might be among the important parameters, which could affect the clinical longevity of CAD/CAM, all ceramic crowns. Since the factors that might influence the vertical marginal gap could also affect the internal fit of $\mathrm{CAD} / \mathrm{CAM}$ all ceramic restoration, it was found to be useful and realistic to discuss the results of the vertical marginal gap in conjunction and relation to the results of internal fit. The vertical marginal gap and the internal fit of crown restoration could be affected by the CAM fabrication technique, geometry of the preparation and strength of the ceramic material. ${ }^{25}$ This study investigated two types of monolithic ceramic system (translucent fully contoured zirconia crowns) that was in order to exclude the possible effect of veneering technique particularly on the vertical marginal gap. The vertical marginal gap without cementation was measured in order to exclude the effect of the cement material on the gap that is to limit the results to be only dependent on the accuracy of the milling machine. In other studies that evaluated vertical marginal gap; one measurement per each surface, giving four measurements per specimen. In the present study eight measurements were taken per each surface leading to thirty-two measurements per specimen. Increasing the number of measurements allowed obtaining more accurate information about the vertical marginal gap regardless of whether the measurement sites were selected in a predetermined or random manner as reported by Groten et al 2000.$^{26}$ Bindl A and Mörmann WH 2007 ${ }^{27}$ reported that clinically accepted marginal discrepancy for $\mathrm{CAD} / \mathrm{CAM}$ fabricated all ceramic crown is $120 \mu \mathrm{m}$ and marginal gap $<80 \mu \mathrm{m}$ will not be visible in the oral environment. Although the vertical marginal gap of Incoris TZI crowns $(59.17 \pm 6.4 \mu \mathrm{m})$ appeared to be less than that of the Prettau crowns $(96.91 \pm 2.78 \mu \mathrm{m})$; both fall within the clinically acceptable range. Internal fit measurement for Incoris TZI $(102 \mu \mathrm{m})$ crowns were also better than that of Prettau crowns $(117 \mu \mathrm{m})$ and also came in agreement with the clinically acceptable range by Balaji $N$ et al $(2015)^{28}$. The better marginal gap and internal fit results of IncorisTZI crowns over that of Prettau could be justified in the light of the accuracy of the milling machine. Incoris TZI crowns were fabricated through milling in 5-axis milling machines while Prettau crowns were milled in 4-axis milling machine. Bosch G et al (2014) ${ }^{29}$ reported that 5-axis milling machines proved to have better marginal gap and internal fit than that of 4-axis milling machines. Furthermore the size of the milling burs could possibly have an effect on the marginal and internal fit. The smaller diameter of Cerec MX5 carbide bur (2.5 mm used for milling of Incoris TZI) "Shaper 25 RZ" than that of ZirkonZahn M1 milling bur zirconia ( $3 \mathrm{~mm}$ used for milling of Prettau) could be also held responsible for the better fit and marginal gap of Incoris TZI crowns than that of Prettau crowns. This scientific assumption could be in agreement with Bosch $\boldsymbol{G}$ et al (2014), ${ }^{21}$ who emphasized on the importance of smaller diameter milling burs in obtaining more accurately milled restoration. The difference in the marginal gap and internal fit between the two types of investigated zirconia could be attributed not only to difference in accuracy of the CAM processing machine, but also and more importantly to the degree of pre-sintering of each type of zirconia. Both Incoris TZI and Prettau zirconia are supplied from the manufacturer in a pre-sintered state. The degree of pre-sintering of Prettau is reported ${ }^{30}$ to be less than that of Incoris TZI, which means that Prettau was supplied in less harder state. The higher degree of pre-sintering of Incoris TZI could be held responsible for the better marginal and internal fit of Incoris TZI than that of Prettau. Beuer F et al $\mathbf{2 0 0 8}^{22}$ reported that higher the degree of pre-sintering of zirconia results in a reduction of shrinkage factor and enables less sinter 
distortion and subsequently better marginal integrity and internal fit. Moreover, Incoris TZI zirconia is reported to have higher mechanical properties than that of Prettau zirconia., ${ }^{31,32}$ Therefore it could be assumed that during the milling of Incoris TZI restorations, they were subjected to less chipping than those of Prettau restorations, with subsequent better adaptation around the margins and axial walls of the prepared dies. This scientific assumption could be in agreement with Shaker A, 2014 ${ }^{33}$ who found that the chipping behavior of machinable materials is related to its microstructure as the harder is the material the less chipping and subsequently better adaptation. The vertical marginal gap of the Incoris TZI crowns and Prettau crowns seemed to be in agreements with results of Balaji $N$ Rajan et al (2015) $)^{20}$ and Ji MK et al ((2015) ${ }^{34}$ respectively.

\section{Limitation of the study}

There is limitation about this study that it involve only two types of monolithic zirconium other types should be included in further studies. Also there is no thermo-cycling aging for the crowns.

\section{CONCLUSIONS}

Within the limitation of this study it could be concluded that Incoris TZI crowns showed better marginal integrity and internal fit than that of Prettau crowns. Both systems produce zirconium crowns that have marginal gap and internal fit that lay within the clinial acceptable range.

\section{REFERENCES}

1. Filser F, Kocher P, Weibel F, Lüthy H, Schärer P, Gauckler LJ. Reliability and strength of all-ceramic dental restorations fabricated by direct ceramic machining (DCM) Int J Comput Dent. 2001;4:89-106.

2. Conrad HJ, Seong WJ, Pesun IJ. Current ceramic materials and systems with clinical recommendations: a systematic review. J Prosthet Dent. 2007;98:389-404

3. Christel P, Meunier A, Heller M, Torre JP, Peille CN. Mechanical properties and short-term in-vivo evaluation of yttrium-oxide-partially-stabilized zirconia. J Biomed Mater Res. 1989;23:45-61.

4. Kugel G, Perry RD, Aboushala A. Restoring anterior maxillary dentition using alumina- and zirconia-based CAD/CAM restorations. Compend Contin Educ Dent. 2003;24:569-572. 574, 576 .

5. Rekow D. Computer-aided design and manufacturing in dentistry: a review of the state of the art. J Prosthet Dent. 1987;58:512-516.

6. Yin L, Song XF, Song YL, Huang T, Li J. An overview of in vitro abrasive finishing \& CAD/CAM of bioceramics in restorative dentistry. Int $\mathrm{J}$ Mach Tool Manuf. 2006;46:1013-1026.

7. Felton DA, Kanoy BE, Bayne SC, Wirthman GP. Effect of in vivo crown margin discrepancies on periodontal health. J Prosthet Dent. 1991;65:357-364.

8. Kokubo Y, Ohkubo C, Tsumita M, Miyashita A, Vult von Steyern P, Fukushima S. Clinical marginal and internal gaps of Procera AllCeram crowns. J Oral Rehabil. 2005 Jul;32(7):526-30.

9. Boening KW, Wolf $\mathrm{BH}$, Schmidt $\mathrm{AE}$, Kästner K, Walter MH. Clinical fit of Procera AllCeram crowns. J Prosthet Dent. 2000;84:419-424.

10. May KB, Russell MM, Razzoog ME, Lang BR. Precision of fit: the Procera AllCeram crown. J Prosthet Dent. 1998 Oct;80(4):394-404

11. Weaver JD, Johnson GH, Bales DJ. Marginal adaptation of castable ceramic crowns. J Prosthet Dent. 1991;66:747753.

12. McLean JW, von Fraunhofer JA. The estimation of cement film thickness by an in vivo technique. Br Dent $\mathrm{J}$. 1971;131:107-111

13. Beuer F, Stimmelmayr M, Gueth J. et al. In vitro performance of full-contour zirconia single crowns. Dent Mater. 2012;28:449_456.

14. Zhang Y, Lee JJW, Srikanth R, et al. Edge chipping and flexural resistance of monolithic ceramics. Dent Mater 2013;29:1201_1208.

15. Mormann WH, Stawarczyk B, Ender A, et al. Wear characteristics of current aesthetic dental restorative CAD/ CAM materials: two-body wear, gloss retention, roughness and Martens hardness. J Mech Behav Biomed Mater. 2013;20:113-125 
16. Sabrah AH, Cook NB, Luangruangrong P, et al. Full-contour Y-TZP ceramic surface roughness effect on synthetic hydroxyapatite wear. Dent Mater. 2013;29:666-673.

17. Alghazzawi TF, Lemons J, Liu PR, et al. Influence of low temperature environmental exposure on the mechanical properties and structural stability of dental zirconia. J Prosthodont. 2012;21:363-369.

18. Seok JH and Jin HC. Comparison of the fit accuracy of zirconia-based prostheses generated by two CAD/CAM systems. J. adv. Prosth. 2016 Dec; 8(6):439-448

19. Freire Y, Gonzalo E., Lopez S., Suarez MJ. The marginal fit of CAD/CAM monolithic cermic and metal ceramic crowns. J. Prosthdont. 2017 Feb; 10.1111/jopr.12590.

20. Awad DS., . Shear bond strength of different adhesive resin cements to dentin EGY. Dent. J. 2017; 63(4) 1595-603.

21. Sailer I, Makarov NA, Thoma DS, Zwahlen M, Pjetursson BE. All-ceramic or metal-ceramic tooth-supported fixed dental prostheses (FDPs)? A systematic review of the survival and complication rates. Part I: Single crowns. Dent Mater. 2015 Jun; 31(6): 603-23.

22. Pang Z, Chughtai A, Sailer A, Zhang Y. A fractographic study of clinically retrieved zirconia-ceramic and metalceramic fixed dental prostheses. Dent Mater. 2015 Oct; 31(10): 1198-206.

23. Rinke S, Hüls A, and Jahn L. Marginal accuracy and fracture strength of conventional and copy-milled all-ceramic crowns. Int J Prosthodont 1995; 8 (4): 303-10.

24. Groten M, and Pröbster L. The influence of different cementation modes on the fracture resistance of feldspathic ceramic crowns. Int J Prosthodont 1997; 10 (2): 169-77.
25. Martinez-Rus F, Suaez MJ, Rivera B, Pardies G. Evaluation of the absolute marginal discrepancy of zirconia-based ceramic copings. J Prosthet Dent. 2011 Feb; 105(2): 108-14.

26. Groten M, Axmann D, Probster L, and Weber H. Determination of the minimum number of marginal gap measurements required for practical in vitro testing. J Prosthe Dent 2000; 83: 40-9.

27. Bindl A and Mörmann WH. Fit of all-ceramic posterior fixed partial denture frameworks in vitro. Int $\mathrm{J}$ of Periodontics \& Restorative Dentistry 2007; 27: 567-575.

28. Balaji N, Srinivasan J, Baburajan Kandhasamy, Ilankumaran R. Evaluation of marginal fit and internal adaptation of zirconia copings fabricated by two CAD - CAM systems: An in vitro study. J Indian Prosthe. 2015 Jul 3; 15(2): 173-178.

29. Bosch G, Ender A, Mehl A. A 3-dimensional accuracy analysis of chairside CAD/CAM milling processes. J Prosthet Dent. 2014 Dec; 112(6): 1425-31.

30. Beuer F, Schweiger J, Edelhoff D. Digital dentistry: an overview of recent developments for CAD/CAM generated restorations. British Dental Journal 2008; 204: 505 - 511.

31. www.manuals.sirona.com/home.HomeDmsdocument. download.html?id=3833

32. www.zirkonzahn.com/en/products/millable-materials/ prettau-zirconia.

33. Shaker A. Chipping tendency of different machinable glass ceramic restorations. Egyptian Dent J. 2014; 60:839-50.

34. JI MK, Park JH, Park SW, Yun KD, OH GJ Lim HP. Evaluation of marginal fit of 2 CAD-CAM anatomic contour zirconia crown systems and lithium disilicate glass-ceramic crown. J Adv Prosthodont. 2015 Aug; 7(4): 271-7. 